Original Article (short paper)

\title{
Player turnover and team performance in FIFA Women's World Cup
}

\author{
Júlia Barreira1@, Gabriela Carvalho de Sousa ${ }^{2}$, Larissa Rafaela Galatti ${ }^{1,2}$ (i) \\ ${ }^{1}$ Universidade Estadual de Campinas, Faculdade de Educação Física, Campinas, SP, Brasil; \\ ${ }^{2}$ Universidade Estadual de Campinas, Faculdade de Ciências Aplicadas, Limeira, SP, Brasil
}

\begin{abstract}
Aims: The specific aims of this study were to characterize player turnover on FIFA Women's World Cup (1991-2015), and to explore the relationship between the turnover rate and team performance. Methods: We analyzed the seven national teams that participated in all of the seasons of the women's World Cup: Brazil, Germany, Japan, Nigeria, Norway, Sweden, and the USA. The full name of the players was used to analyze which athlete was maintained or substituted from a season to another. The names of the players were retrieved from the official FIFA website. Player turnover was measured by the percentage of players that were on a team in one season and were not on the roster on the following edition. The performance was measured by the final classification of the teams. Results: The results showed that most players participated only in one season of the championship. An average rate of $53 \%$ of player turnover per team was found by edition, which represents, approximately, 13 substituted athletes. Medalist teams showed lower player turnover $(48 \%)$ compared to the non-medalist teams $(57 \%)(\mathrm{p}$-value $=0.0305 ; \mathrm{ES}=0.69)$. Furthermore, teams that were classified for the quarterfinals decreased player turnover in the next season ( $p$-value $=0.0408, E S=0.89$ ), maintaining a good performance $\left(\chi^{2}=4.114\right.$, $\mathrm{p}$-value $\left.=0.042\right)$. We could not find any influence of higher turnover rates on team performance $\left(\chi^{2}=0.535\right.$, $p$-value $\left.=0.464\right)$. Conclusion: The present study found that lower rates of player turnover may be beneficial for team performance in the FIFA Women's World Cup. When successful teams decrease their turnover rate, sports performance seems to be maintained.
\end{abstract}

Keywords: team sports; sports coaching; performance analysis; human resources management.

\section{Introduction}

On the eve of the World Cups, sports fans are often eager to meet the summoned players that will compose the national team and represent their country. On that specific moment, the coaching side of each sports fan emerges, and each individual selects 22 players aiming at maximizing the national team performance. This process may be guided by the previous summoning and by the conventional wisdom saying "don't change a winning team". Therefore, the choice for maintaining or changing a player throughout the seasons may be based on his or her previous performance and the supposed relationship between player turnover and team performance. Although the relationship between player turnover and team performance is well established by sports fans, it is necessary to investigate this hypothesis scientifically.

The process of composing a team is a challenge for both sport managers, coaches, and team staffing. Great attention is given to the process of selecting and dismissing athletes when aiming to improve the sport and/or financial performance. This process of the outflow and inflow of people from an organization is called turnover ${ }^{1}$ and has been widely explored in the management and applied psychology research $^{2,3}$. The main issue studied is the relationship between employee turnover and firm performance and the negative effects of high turnover is well-documented ${ }^{4,5}$. Although the turnover is a usual process in team sports in general, the phenomenon has not received the same attention by sports scientists.

Previous studies in the sports area have explored the relationship between player turnover and match attendance in baseball $^{6}$ and basketball ${ }^{7}$ national championships. In these studies, the authors showed an average turnover of $27 \%^{6}$ and $36 \%{ }^{7}$ per team in a one-year season. Some questions may arise from these results, such as how was the turnover variability between the teams and if the turnover influenced team performance. This knowledge would provide valuable information to support the decisions regarding recruitment and dismission of players. This study aims to promote an initial exploration and discussion on the relationship between player turnover and team performance. We have no intention to propose a simple and universal relationship between these two variables. On the contrary, we aim to bring a new variable into account when building a sports team.

Therefore, the goal of this study was to analyze player turnover in the FIFA Women's World Cup (WC). The specific aims of this research were to characterize player turnover on women's WC and to explore the relationship between turnover rate and team performance. It is important to highlight the reasons for choosing this specific championship. First, the analysis of international competitions such as the World Cup and the Olympics provides valuable information about trends and competitiveness between elite football players. Second, 
the first women's WC was held in 1991 and since then seven national teams have participated in all of the seasons. This provides longitudinal data which can be used to explore the pattern of player turnover in and after winning seasons. At last, the database is composed of a sufficient number of cases to explore the effects of higher and lower rates of player turnover on team performance.

\section{Theoretical framework}

As shown above, the issue of employee turnover has a long history in management and applied psychology research ${ }^{2}$. Although not all of the concepts from the managerial area can be simply applied to the field of sports science, they may be a useful framework to begin the exploration of this theme.

A negative relationship between turnover rates and organizational outcomes have been shown by several studies ${ }^{4,5,8}$. In general, three theoretical frameworks have been accepted to explain the effect of turnover rates on organizational performance: i) cost-based perspective; ii) human capital perspective; iii) social capital perspective. According to Allen, Bryant, \& Vardaman', some expenditures are related to separation costs, such as benefits, accrued vacation time and temporary coverage; while others costs are related to replacement, such as recruitment, selection, orientation, and training. These expenditures represent the cost-based perspective. The human capital theory suggests that a firm is negatively impacted by the departure of a trained employee because it leads to the loss of skill and knowledge that have economic value to the organization ${ }^{10,11}$. Although human capital is seen as the main determinant of performance, the social damage caused by employee exit has also a significant impact on organization performance ${ }^{12,13}$. According to these previous studies, social capital has a positive influence on organizational performance because relationships may enhance commitment, increase flexibility, and foster intellectual capital. Once this network is disrupted by an employee exit, the organizational performance may be negatively affected.

Based on the previous studies in the managerial area, we hypothesize that low rates of player turnover will positively affect team performance. Similarly, a high turnover rate may reflect the several performance problems faced by the group ${ }^{2}$, in which the turnover could be induced by the search for immediate solutions. The three main perspectives presented earlier (costbased perspective; human capital perspective; social capital perspective) may be useful to understand the relationship between the player exit and team performance.

In the current scenario of a professional team sport, the player is seen as a product. The process of transferring an athlete from a team to another involves negotiation and costs. The demands of paying salary, benefits, and vacation seem to have a similar negative effect on the club profit as well as on firm performance. However, this cost-based perspective may not be applicable on national teams, in which there is no (direct) cost involved in the summoning or dismission of an athlete; in this case, the costs evolve time and effort to adjust the player to the new context. According to Green ${ }^{14}$, the athlete may face several symptoms in this transition to a new team, such as a sense of stress, feeling of loss and deprivation as compared with old friends, fears of rejection, confusion about role identity, disorientation, and feelings of inadequacy. Therefore, this process may lead to immediate negative consequences on the player and team performance.

The human capital perspective is based on the knowledge and skills of athletes have developed through experience and training and may be useful in understanding why a low turnover rate may be more beneficial for team performance. The experience seems to have a greater importance in the context of international championships, such as the World Cup, due to the high pressure for performance coupled to a high attendance in the stadiums ${ }^{15}$. This hypothesis is corroborated by previous studies with women's and men's football that have already shown the importance of maintaining older and experienced athletes for the team success. The study on women's football teams participating in the 2012 Olympic Games showed a high correlation between team average age and sport performance ${ }^{16}$. Similarly, Kalén, Rey, de RellánGuerra, Lago-Peñas ${ }^{17}$ analyzed the evolution of male players' age in the UEFA Champions League and found an aging trend in the last three decades. In men's football, it was also shown that the number of experienced players in finalist teams in World Cups was significantly higher than in non-finalist teams ${ }^{18}$. Based on the human capital framework, the maintenance of older and experienced players may be an effective strategy to achieve better performances.

The social capital perspective may also be able to explain the likely impact of player turnover on team performance. According to Berman, Down, \& Hill19 "a team needs time to jell". The success in team sports requires a high level of collaboration among teammates, and the longer they play together the more they learn how to combine their efforts into a coherent whole ${ }^{19}$. Athletes that have worked together for a long time are conscious about one another's roles and are capable to anticipate a teammate's move, which may result in enhanced team performance. Therefore, it is expected that a successful team is likely to be maintained and the players will have a high level of shared experience ${ }^{20}$. For that reason, successful teams may tend to be maintained from a season to another, while unsuccessful teams tend to increase player turnover aiming to improve sports performance.

\section{Methods}

\section{Sample}

To explore player turnover throughout FIFA Women's World Cup (1991-2015) we analyzed the seven national teams that participated in all seasons of the competition: Brazil, Germany, Japan, Nigeria, Norway, Sweden, and the U.S.A. From each team, we collected the names of the rosters in each season. All the data was obtained from the official website of the Federation International of Football Association (www. fifa.com). The data used in this study is in the public domain and is available online. 


\section{Procedures}

The data collection was carried out by two researchers to assure data reliability. The full name of the players was used to analyze which athlete was maintained or substituted from a season to another. The main variable of interest (dependent variable) was based on the work of Kahane \& Shmanske ${ }^{6}$ and Morse, Shapiro, McEvoy, \& Rascher ${ }^{7}$ in which player turnover represents the percentage of players on a team in a season who were not on the roster the following season. This procedure was used to calculate player turnover by a national team from a season to another (independent variables).

Team performance was also used as an independent variable. The performance was measured by the final position of the national team in each season. Medalist teams were considered as successful and non-medalists as non-successful performance, as used in previous studies ${ }^{21,22}$.

\section{Statistical analysis}

Descriptive statistics (mean, standard deviation and charts) were used to explore and summarize the collected data. Inferential statistics were used to analyze the relationship between the dependent and independent variables. The data normality was evaluated using the Shapiro-Wilk test. We first conducted a comparison of player turnover between the national teams, using the Analysis of Variance (ANOVA) for independent samples, to assure that the relationship between player turnover and team performance was not influenced by nationality. The comparison of player turnover between medalist and non-medalist teams was performed using the T-test for independent samples. The same test was used to compare the turnover rates of winning teams from a season to the next one. A significance level of 0.05 was adopted and Cohen's d Effect Size (ES) was used to analyze the magnitude of the effect. The Rhea ${ }^{23}$ classification for highly trained individuals was used to interpret the ES. It was considered: trivial $<0.25 ; 0.25<$ small $<0.50 ; 0.50<$ moderate $<1.0$; large $>1.0$. The Chi-squared test was used to analyze the relationship between player turnover and team performance from a season to the next. All the data were tabulated and arranged in a Microsoft Excel worksheet, followed by export to GraphPad Prism software which was used for all the statistical analyses.

\section{Results}

In this study, we analyzed 575 women's football players that participated in at least one FIFA World Cup. Figure 1 shows the frequency of the athletes' participation in the competition. Most of the players participated in only one season. The participation can be described by an exponential decay in which only two athletes participated six times in the competition, the highest frequency found.

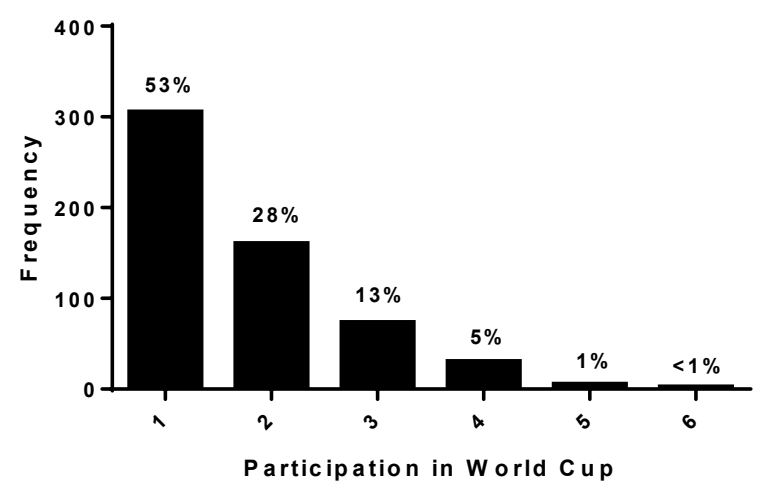

Figure 1. Women's football players participation in FIFA World Cups.

Table 1 shows the player turnover and classification of the national teams throughout the years. No significant difference was found in player turnover between the national teams $(p$-value $=0.546)$. The average player turnover per team by season was $53 \pm 11 \%$.

Table 1. Player turnover and classification of the national teams throughout the years.

\begin{tabular}{|c|c|c|c|c|c|c|c|}
\hline & Brazil & Germany & Japan & Nigeria & Norway & Sweden & U.S.A. \\
\hline 1995 & $50 \%$ & $78 \%$ & $56 \%$ & $39 \%$ & $56 \%$ & $61 \%$ & $56 \%$ \\
\hline Position & $\mathrm{NC}$ & $2^{\text {th }}$ & QF & $\mathrm{NC}$ & $1^{\text {th }}$ & QF & $3^{\text {th }}$ \\
\hline 1999 & $60 \%$ & $55 \%$ & $60 \%$ & $50 \%$ & $65 \%$ & $80 \%$ & $45 \%$ \\
\hline Position & $2^{\text {th }}$ & $\mathrm{QF}$ & $\mathrm{NC}$ & $\mathrm{QF}$ & $\mathrm{QF}$ & $\mathrm{QF}$ & $1^{\text {th }}$ \\
\hline 2003 & $65 \%$ & $50 \%$ & $55 \%$ & $60 \%$ & $50 \%$ & $50 \%$ & $40 \%$ \\
\hline Position & QF & $1^{\text {th }}$ & $\mathrm{NC}$ & $\mathrm{NC}$ & QF & $2^{\text {th }}$ & $3^{\text {th }}$ \\
\hline 2007 & $45 \%$ & $45 \%$ & $55 \%$ & $60 \%$ & $65 \%$ & $55 \%$ & $55 \%$ \\
\hline Position & $2^{\text {th }}$ & $1^{\text {th }}$ & $\mathrm{NC}$ & $\mathrm{NC}$ & QF & $\mathrm{NC}$ & $3^{\text {th }}$ \\
\hline 2011 & $43 \%$ & $38 \%$ & $48 \%$ & $62 \%$ & $62 \%$ & $43 \%$ & $52 \%$ \\
\hline Position & QF & QF & $1^{\text {th }}$ & $\mathrm{NC}$ & $\mathrm{NC}$ & $3^{\text {th }}$ & $2^{\text {th }}$ \\
\hline
\end{tabular}


Table 1. Continued.

\begin{tabular}{lccccccc}
\hline & Brazil & Germany & Japan & Nigeria & Norway & Sweden & U.S.A. \\
\hline 2015 & $62 \%$ & $52 \%$ & $19 \%$ & $67 \%$ & $48 \%$ & $48 \%$ & $38 \%$ \\
\hline Position & NC & QF & $2^{\text {th }}$ & NC & NC & NC & $11^{\text {th }}$ \\
\hline Mean & $54 \%$ & $53 \%$ & $49 \%$ & $56 \%$ & $58 \%$ & $56 \%$ & $48 \%$ \\
STD & $9 \%$ & $14 \%$ & $15 \%$ & $10 \%$ & $8 \%$ & $13 \%$ & $8 \%$ \\
\hline
\end{tabular}

Legend: NC - Non-classified for quarterfinals; QF - Classified for quarterfinals; 1th, 2th and 3th places.

The medalist teams $(48 \pm 12 \%)$ showed a significantly lower player turnover compared to the non-medalist teams $(56 \pm 9 \%)$ ( $p$-value $=0.0305 ; E S=0.69$ ). Figure 2 shows the turnover rates of the national teams when they won first or second place (Winning Season) and their respectively turnover rates in the next season. The national teams that compose the sample of this study were champion or vice-champion eight times in FIFA Women's World Cup. Only one case showed an increase, from $50 \%$ to $55 \%$, in turnover rate from the winning season to the next one. In all other cases, turnover decreased after the winning season. Therefore, data showed a significant decrease in turnover rates from the winning season to the next $(\mathrm{p}$-value $=0.0408, \mathrm{ES}=0.89)$.

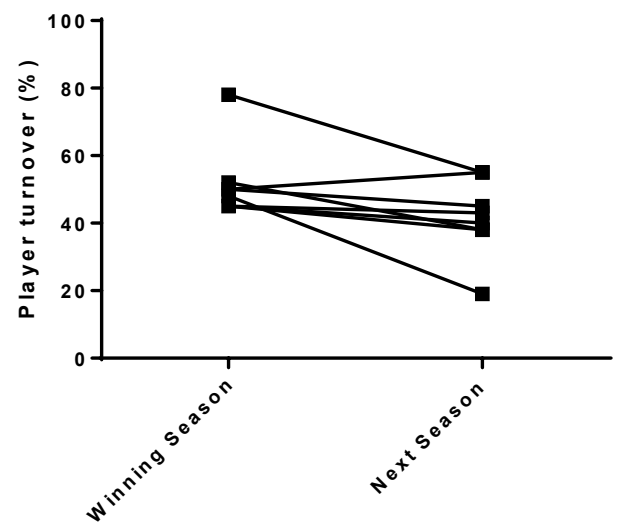

Figure 2. Turnover of players from different positions.

Table 2 shows the influence of player turnover on team performance in the next season. The performance was measured by the classification, or non-classification, of the national teams for the quarterfinals. The results show that increasing the turnover rate does not influence on team classification regardless of its previous performance. However, it was found a significantly higher frequency of classified teams when successful teams decreased their turnover rate.

Table 2. Relationship between team performance and turnover rate from a season to the next.

\begin{tabular}{cccccc}
\hline \multicolumn{5}{c}{$\begin{array}{c}\text { Next } \\
\text { season }\end{array}$} & Previous season \\
\hline \multirow{2}{*}{$\begin{array}{c}\text { Higher } \\
\text { turnover }\end{array}$} & Classifified & $6(18 \%)$ & $\begin{array}{c}\text { Non- } \\
\text { classified }\end{array}$ & $\chi^{2}$ & p-value \\
\cline { 2 - 6 } & Non-classified & $4(12 \%)$ & $3(9 \%)$ & 0.535 & 0.464 \\
Lower & Classified & $13(39 \%)$ & $2(6 \%)$ & 4.114 & 0.042 \\
turnover & Non-classified & $1(3 \%)$ & $2(6 \%)$ & & \\
\hline
\end{tabular}

Legend: Classified or non-classified for quarterfinals. In two cases the turnover rate was the same in consecutive seasons; for that reason, they are not added to the table.

\section{Discussion}

In this study, we analyzed player turnover in the seven national teams that have participated in all of the FIFA Women's World Cup (1991-2015). The main findings of this study showed that i) most of the players participated in only one season of the championship; ii) the medalist teams present a lower player turnover compared to the non-medalist teams; iii) the winning teams show a significant decrease in turnover rates from the winning season to the next, in which the good performance is maintained. This first study exploring the influence of player turnover on team performance allowed a better understanding of the phenomenon and, maybe a useful starting point for future studies into this research topic.

The results of women's football players in the World Cup showed that most of the athletes (54\%) participate only once in the championship. These results reinforce that reaching the elite sport level is a difficult task, however, maintaining the high level of performance is a much greater challenge. Only two athletes participated in six editions of the competition, this was the highest frequency found in this study. This frequency is so rare that the athletes became very famous in the sport context: Formiga, the 40-years-old player that still plays for the Brazilian national team, and Homare Sawa, a Japanese athlete considered the best player of the world in 2011. Durand-Bush and Salmela ${ }^{24}$ suggested that the ability to deal with psychological aspects of competition, such as self-confidence, motivation, creativity, and perseverance, are significant factors to the maintenance of the elite performance, in which experience plays an important role in the development of these abilities.

The results of this study showed an average rate of 53\% of player turnover per season. This means that, approximately, 13 athletes are substituted per team from a season to another. The player turnover rate found in this study is higher than the previous findings in baseball $(27 \%)^{6}$ and basketball teams $(36 \%)^{7}$ in national competitions. There are some differences between our methods and the previous ones which may explain the different findings. The previous studies investigated the turnover rates between a one-year-season in teams that played national competitions. In our study, the player turnover was analyzed in the period of four years in national teams that participated in world championships. It was expected higher turnover rates in our sample due to the longer period between the analyzed seasons. In four years, the athletes have higher chances of injuries or retirement as well as there is a greater competitiveness with the new players.

The medalist teams in FIFA Women's World Cup showed a significantly lower turnover compared to the non-medalist 
teams. A difference of $8 \%$ in the rate of player turnover was found between these groups, which represents approximately two athletes. That is, whether or not selecting two new players for international competition can play an important role in team performance. This result corroborates our initial hypothesis that lower turnover rates would be related to better team performances. Our aim with this study is not establishing a simple and linear relationship between performance and player turnover. On the contrary, we bring a new variable that should be taken into account when building a team and analyzing its success.

Another interesting finding is the fact that successful teams decreased their turnover rate to the next season maintaining a good performance. This means that maintaining athletes of successful teams seems to be a good strategy to sustain sports performance. These results show that the common wisdom "don't change a winning team" can be found in elite teams, at least in women's football. According to Katz \& Koenig ${ }^{20}$ "it seems reasonable to expect that a team that wins is likely to be kept intact, so team members, therefore, have a high level of shared experience". Once again, human and social capital may play an important role when maintaining teammates together for a longer period and improving team performance.

The human capital may be characterized by the skills and knowledge that players acquire with experience. International championships, such as the World Cup, are characterized by full stadiums with a high demand for sports performance. Athletes' performance might be negatively affected by the stressful environment if they are not familiarized with it. Nicholls and Polman ${ }^{25}$ suggest that previous experiences in a competition is important for the development of coping strategies and effectiveness. Furthermore, the presence of experienced athletes may play an important role in helping younger players to face this challenge.

The social capital may also contribute to explain our findings. According to Berman, Down, \& Hill $^{19}$ a low turnover in a group may facilitate the "ability of members to draw upon experientially constructed schemata to operate in synchronously". The connections and interactions developed between the players over time may facilitate the ability to anticipate the teammates' moves and actions. Therefore, relationships may booster the team tactical performance. Maintaining the athletes in the same team, promoting interactions inside and outside of the field may be interesting strategies to increase the social capital and consequently team performance.

Although this study brings new insights and discussions regarding the relationship between player turnover and team performance, it is important to recognize the limitations of our work. Based on the lower number of unsuccessful teams of our sample, we could not explore the consequences of turnover rate on their sports performance. Therefore, these results should be further explored in future studies. We also did not analyze variables that should have led to the leaving of players, such as age, being a starter or non-starter athlete and their positions. In the same way, we explored the turnover of only summoned players and not in playing athletes. All these questions could be investigated by future works. At last, it is important to recognize that our study was conducted with FIFA Women's World Cup, using the final classification of the teams as a performance indicator. More studies on the player turnover with other sports and championships, and with different measures of performance, would provide a better understanding of the phenomenon.

\section{Conclusion}

The present study found that lower rates of player turnover may be beneficial to team performance in the FIFA Women's World Cup. Sport performance seems to be maintained when successful teams decrease their turnover rate. Furthermore, our findings showed that increasing player turnover has no influence (positively or negatively) on team performance. This knowledge may be a piece of valuable information to support the decisions of sport managers, coaches, and team staffing, regarding recruitment and dismission of players.

\section{References}

1. Price JL. The study of turnover. Iowa State University Press; 1977.

2. Heavey AL, Holwerda JA, Hausknecht JP. Causes and consequences of collective turnover: A meta-analytic review. J Appl Psychol. 2013;98(3):412-53.

3. Hom PW, Lee TW, Shaw JD, Hausknecht JP. One hundred years of employee turnover theory and research. J Appl Psychol. 2017;102(3):530-45.

4. Park T-Y, Shaw JD. Turnover rates and organizational performance: A meta-analysis. J Appl Psychol. 2013;98(2):268-309.

5. Hancock JI, Allen DG, Bosco FA, McDaniel KR, Pierce CA. Meta-Analytic Review of Employee Turnover as a Predictor of Firm Performance. J Manage 2013;39(3):573-603.

6. Kahane LH, Shmanske S. Team roster turnover and attendance in major league base. Appl Econ. 1997;29:425-31.

7. Morse AL, Shapiro SL, McEvoy CD, Rascher DA. The Effects of Roster Turnover on Demand in the National Basketball Association Recommended Citation. Int J Sport Financ. 2008;3:8-18.

8. Ongori H. A review of the literature on employee turnover. African J Bus Manag. 2007;1(2):49-54.

9. Allen DG, Bryant PC, Vardaman JM. Retaining Talent: Replacing Misconceptions With Evidence-Based Strategies. Acad Manag Perspect. 2010;24(2):48-64.

10. Becker GS. Investment in Human Capital: A Theoretical Analysis. J Polit Econ. 1962;70(5, Part 2):9-49.

11. Snell SA, Dean JW. Integrated Manufacturing and Human Resource Management: A Human Capital Perspective. Acad Manag J. 1992;35(3):467-504.

12. Dess GG, Shaw JD. Voluntary Turnover, Social Capital, and Organizational Performance. Acad Manag Ver. 2001;26(3):446-56.

13. Shaw JD, Duffy MK, Johnson JL, Lockhart DE. Turnover, Social Capital Losses, and Performance. Acad Manag J. 2005;48(4):594-606. 
14. Green BC. Building Sport Programs to Optimize Athlete Recruitment, Retention, and Transition: Toward a Normative Theory of Sport Development. J Sport Manag. 2005;19(3):233-53

15. Galatti LR, Paes RR, Machado GV, Gonçalves CB, Seoane AM, Galatti LR, et al. Determinants of excellence in female basketball: achievements of the brazilian selection in the athletes' view. Rev da Educ Física/UEM. 2015;26(4):621.

16. Barreira J. Age of Peak Performance of Elite Women's Soccer Players. Int J Sport Sci. 2016;6(3):121-4.

17. Kalén A, Rey E, de Rellán-Guerra AS, Lago-Peñas C. Are soccer players older now than before? Aging trends and market value in the last three decades of the UEFA champions league. Front Psychol. 2019;10(1):1-6.

18. Kobal R, Barroso R, Abad CCC, Kitamura K, Carmo EC do, Pereira L, et al. Previous participation in FIFA World-Cup: the key to success? Mot Rev Educ Física. 2016;22(2):73-9.

19. Berman SL, Down J, Hill CWL. Tacit Knowledge as a Source of Competitive Advantage in the National Basketball Association. Acad Manag J. 2002;45(1):13-31.

20. Katz N, Koenig G. Sports teams as a model for workplace teams: Lessons and liabilities. Acad Manag Persp. 2001;15(3):56-67.

21. Cular D, Krstulovic S, Tomljanovic M. The differences between medalists and non-medalists at the 2008 olympic games taekwondo tournament. Biol Sport. 2011;12(2):165-70.

22. Sitkowski D. Some indices distinguishing Olympic or world championship medallists in sprint kayaking. Hum Mov. 2015;12(2):165-70.
23. Rhea MR. Determining the Magnitude of Treatment Effects in Strength Training Research Through the Use of the Effect Size. J Strength Cond Res. 2004;18(4):918.

24. Durand-Bush N, Salmela JH, Durand-Bush N, Salmela JH. The Development and Maintenance of Expert Athletic Performance: Perceptions of World and Olympic Champions. J Appl Sport Psychol. 2002;14:154-71.

25. Nicholls AR, Polman RCJ. Coping in sport: A systematic review. J Sports Sci. 2007;25(1):11-31.

\section{Corresponding author}

Júlia Barreira

Av. Érico Veríssimo, 701, Barão Geraldo, Campinas SP, Brasil. CEP: 13083-851.

Email: jubarreira2@hotmail.com

Manuscript received on January 24, 2019

Manuscript accepted on May 15, 2019

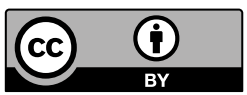

Motriz. The Journal of Physical Education. UNESP. Rio Claro, SP, Brazil - eISSN: 1980-6574 - under a license Creative Commons - Version 4.0 